Bull. Chem. Soc. Ethiop. 2021, 35(1), 119-128.

(C) 2021 Chemical Society of Ethiopia and The Authors

ISSN 1011-3924

DOI: https://dx.doi.org/10.4314/bcse.v35i1.10

Printed in Ethiopia

Online ISSN 1726-801X

\title{
LUMINESCENT, SORPTIVE AND ANTIBACTERIAL POTENTIAL OF BISMUTH-ORGANIC FRAMEWORK
}

\author{
Shamaila Iram ${ }^{1}$, Tamkanat Khurshid ${ }^{1}$, Shoomaila Latif ${ }^{2 *}$, Muhammad Imran ${ }^{1}$, \\ Farah Kanwal $^{1}$ and Liviu Mitu ${ }^{3 *}$ \\ ${ }^{1}$ Institute of Chemistry, University of the Punjab, Lahore, Pakistan \\ ${ }^{2}$ School of Physical Science, University of the Punjab, Lahore, Pakistan \\ ${ }^{3}$ Department of Nature Sciences, University of Pitesti, Pitesti, 110040, Romania
}

(Received December 1, 2020; Revised March 19, 2021; Accepted March 27, 2021)

\begin{abstract}
Metal organic frameworks are formed by the three-dimensional linkage of metal cores and organic linkers. In this work, bismuth-based metal organic framework (Bi-MOF) has been synthesized by using 5hydroxyisophthalic acid $\left(\mathrm{H}_{2} \mathrm{HIA}\right)$ as linker via hydrothermal method. The said MOF was structurally characterized by UV/Vis, Fourier transform infrared spectroscopy (FT-IR), scanning electron microscopy (SEM), ${ }^{1} \mathrm{H}$ NMR, energy dispersive spectroscopy (EDS), thermogravimetric analysis (TGA) and X-ray diffraction technique. This MOF showed highly porous structure with surface area $1096 \mathrm{~m}^{2} / \mathrm{g}$ as determined by BET analysis. A model batch adsorption experiment was performed to evaluate the efficiency of methylene blue (MB) dye removal from aqueous media. It was found that monolayer adsorption capacity calculated from the Langmuir isotherm was $0.6240 \mathrm{mg} / \mathrm{g}$. Bi-MOF was also screened for its antibacterial and luminescent behavior.
\end{abstract}

KEY WORDS: Bismuth, Metal-organic Frameworks, Luminescence, Sorption

\section{INTRODUCTION}

Metal-organic frameworks (MOFs) have expanded over the last decade due to their captivating structures as well as potential applications in various fields [1]. These MOFs contained of inorganic ions/or clusters connected via organic linkers to construct a porous 3D network. Several polycarboxylate linkers with a many transition metal ions have been reported [2-4]. The thermal and chemical stability of these carboxylate constructed MOFs are important for variety of potential uses [5]. Bismuth is a p-block element and heavy metal that may increase the flexibility of the resulting structure because of higher and flexible coordination numbers [6-9].

There are several techniques available to remove dyes from aqueous medium. Significance of adsorption over other technique is due to the fact that it is considered a surface occurrence; further in order to understand, modify and optimize the chemical reactions associated with environmental degradation, surface of substrate is of critical significance. By optimizing conditions and modification of sorbent materials by chemical, mechanical or thermal means, removal efficiency of sorption process may be significantly altered. In this manuscript, we report the synthesis of Bi-MOF using 5-hydroxyisophthalic acid $\left(\mathrm{H}_{2} \mathrm{HIA}\right)$, its gas adsorption, luminescence and antibacterial studies. Moreover, removal of MB dye as model study is also part of this paper.

\section{EXPERIMENTAL}

\section{Materials}

5-Hydroxyisophthalic acid was bought from Sigma-Aldrich however bismuth chloride salt was procured from Uni-chem. Melting point is measured by Gallenkamp melting point instrument.

*Corresponding author. E-mail: shoomaila_latif@yahoo.com; ktm7ro@yahoo.com

This work is licensed under the Creative Commons Attribution 4.0 International License 
${ }^{1} \mathrm{H}$ NMR spectrum was recorded on the Avance AV-400 spectrometer. The morphology of the sample was done by FEI, Inspect S50, SEM (scanning electron microscope) and EDS (energy dispersive X-ray spectroscopy). Functional groups of the synthesized sample were identified using FTIR spectrometer (Agilent FTIR spectrophotometer; model CARY-630). Thermogravimetric analysis (TGA) was performed by using the SDT Q600 and TGA 701 instruments under nitrogen at a heating rate of $10{ }^{\circ} \mathrm{C} / \mathrm{min}$ at $30^{\circ}$ to $800{ }^{\circ} \mathrm{C}$. The powder X-ray diffraction pattern was achieved by diffractometer (Equinox 2000, Thermo Scientific, USA) by $\mathrm{CuK} \alpha_{1}$ radiation. The $\mathrm{N}_{2}$ gas adsorption study (BET) was completed with the Tri Star II 3020 form 2.00. Adsorption study was carried out using UV-Vis Spectrophotometer (Labomed spectrophotometer system; model UVD-T90+).

\section{Synthesis of bismuth based MOF}

Bi-MOF was prepared by mixing equimolar solutions of bismuth chloride $(1.0 \mathrm{mmol}, 0.310 \mathrm{~g}$, $20 \mathrm{~mL}$ acetonitrile) and 5-hydroxyisophthalic acid $\left(1.0 \mathrm{mmol}, 0.182 \mathrm{~g}, 10 \mathrm{~mL} \mathrm{CH}_{3} \mathrm{OH}\right)$ at room temperature for $4 \mathrm{~h}$. The obtained solution was concentrated to half, resulting in solid mass. This solid was filtered, washed with methanol, acetonitrile and lastly dried. Dried solid was placed in a desiccator for further use. Calculated yield: $48 \%(202 \mathrm{mg})$; d.T: $>300{ }^{\circ} \mathrm{C}$; FT-IR: v(COO $)_{\text {asym }}$ $1590 \mathrm{~cm}^{-1}, v(\mathrm{COO})_{\text {sym }} 1401 \mathrm{~cm}^{-1} ;{ }^{1} \mathrm{H}$ NMR $\left(400 \mathrm{MHz}, \mathrm{DMSO}-d_{6}\right): \delta(\mathrm{ppm})=8.32-7.51(\mathrm{~m}, 3 \mathrm{H}$, Ar- $\mathrm{H}$ ), 3.32 (bs, $2 \mathrm{H}, \mathrm{H}_{2} \mathrm{O}$ ); analytical data (\%): C, 19.46 (theoretical), 19.31 (experimental); $\mathrm{H}$, 1.38 (1.22); Bi, 42.18 (42.01).

\section{Adsorption experiment}

Adsorption efficiency of the Bi-MOF was studied for the removal of methylene blue. MB dye $(0.1 \mathrm{~g})$ was dissolved in distilled water to form $1000 \mathrm{ppm}$ solution. Dilutions were made to 2, 4, 6,8 and $10 \mathrm{ppm}$, respectively and their absorbance were recorded using a UV-Vis spectrophotometer. The concentration of each dye before and after Bi-MOF addition was determined by a calibration curve to determine the removal efficacy of Bi-MOF material for methylene blue.

Different parameters such as $\mathrm{pH}$, sorbent dose, time, etc. were optimized for the sorption capacity of Bi-MOF. Concentration of dye was determined by UV-Visible spectrophotometer at $\lambda_{\max }=665 \mathrm{~nm}$, by varying and optimizing different parameters. The effect of $\mathrm{pH}$ was studied in the $\mathrm{pH}$ range (2-12) using methylene blue solution $(10 \mathrm{~mL}, 2-10 \mathrm{ppm})$ and Bi-MOF $(5 \mathrm{mg})$. The sorbent dose effect was studied for methylene blue solution $(10 \mathrm{~mL}, 2-10 \mathrm{ppm})$ using Bi-MOF (5-35 $\mathrm{mg})$. The effect of time was studied by varying the time $(5-30 \mathrm{~min})$ while keeping the other parameters constant, i.e. Bi-MOF $(5 \mathrm{mg})$, methylene blue solution $(10 \mathrm{~mL}, 2-10 \mathrm{ppm})$.

\section{Biological investigations}

The antibacterial activity of this Bi-MOF against three bacterial strains was tested. Three Grampositive (Staphylococcus aureus, Clostridium butyricum, Bacillus cereus) and two Gramnegative (Escherichia coli and Enterobacter aerogenes) bacteria in nutrient agar medium with agar hole diffusion system were used for this purpose as per reported procedure [10].

\section{RESULTS AND DISCUSSION}

Bi-MOF was obtained in good yield as outlined in Scheme 1. This MOF is an air stable solid and its solubility is very specific; only having solubility in DMSO. This decreased solubility can be ascribed to its framework/aggregation properties. 


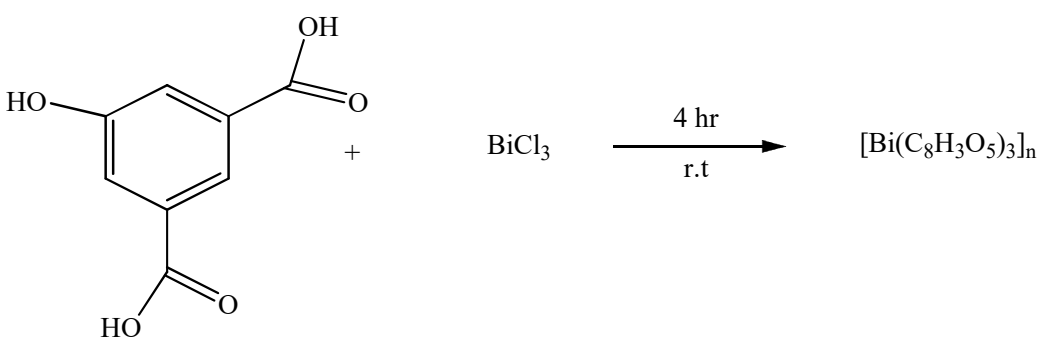

Scheme 1. Reaction scheme for the synthesis of Bi-MOF.

\section{FT-IR spectra}

FT-IR spectroscopy was used to compare functional groups in uncomplexed linker and BiMOF. (Bi-MOF) shows the asymmetric and symmetric stretching modes of carboxylate at 1590 $\mathrm{cm}^{-1}$ and $1401 \mathrm{~cm}^{-1}$, respectively. The $\Delta v$ between $v_{\text {asym }}(\mathrm{COO})$ and $v_{\text {sym }}(\mathrm{COO})$ is $189 \mathrm{~cm}^{-1}$ indicating its bidentate mode of coordination via chelation [11]. The $v \mathrm{OH}$ phenol frequency band at $3100-3300 \mathrm{~cm}^{-1}$ disappears thus providing confirmation for the coordination of hydroxyl oxygen atom with the bismuth(III) ion after deprotonation.

\section{${ }^{1} H$-NMR spectrum}

${ }^{1} \mathrm{H}$ NMR spectrum of Bi-MOF (Figure 1) was recorded using DMSO- $d_{6}$ solvent. ${ }^{1} \mathrm{H}$ NMR spectrum indicates the nonappearance of signals for $-\mathrm{COOH}$ and $-\mathrm{OH}$ (phenol) protons supporting their involvement with bismuth(III) ion via oxygen atoms [12]. Multiple peaks in the $\delta=8.32-7.51 \mathrm{ppm}$ range are attributed to phenyl protons.

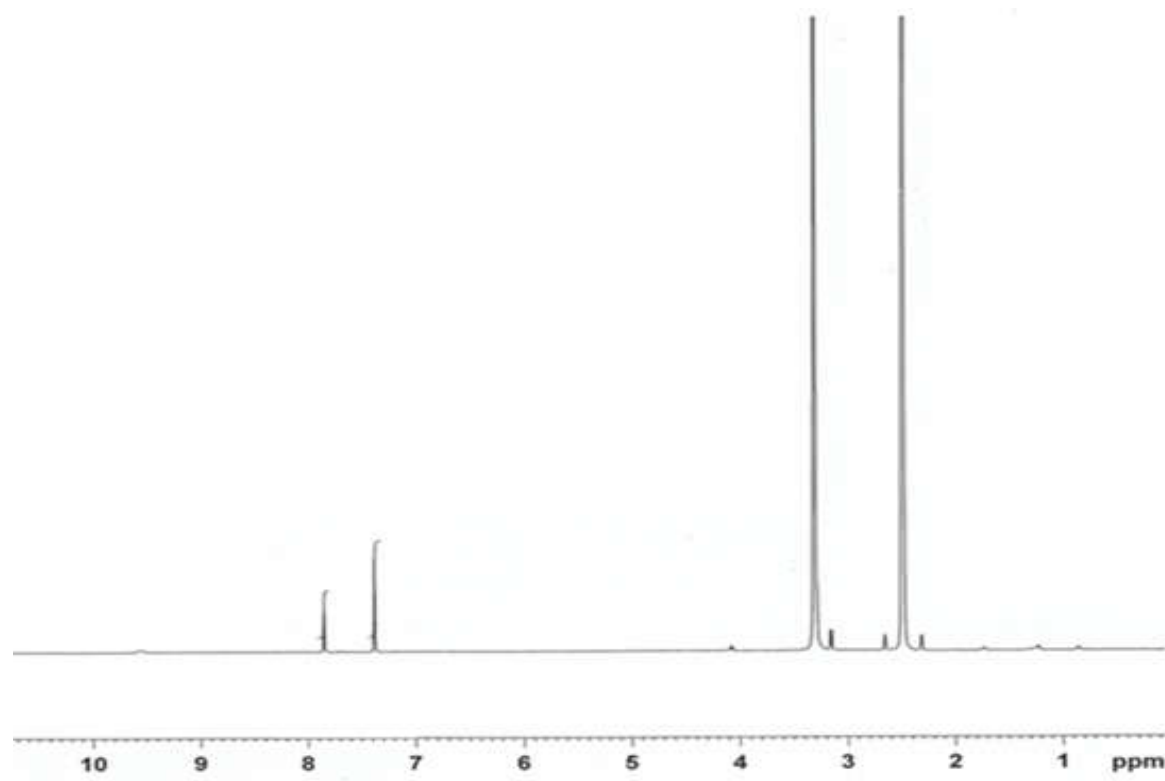

Figure 1. ${ }^{1} \mathrm{H}$ NMR spectrum of bismuth-based MOF. 
Powder X-ray diffraction studies

The diffraction data of the Bi-MOF was obtained by using X-ray powder diffraction technique (Figure 2). The high intensity peaks for Bi-MOF appear at $2 \theta=17.78^{\circ}, 26.34^{\circ}, 27.08^{\circ}$. Hexagonal frame: (unit cell, $\mathrm{a}=4.5367 \AA, \mathrm{c}=5.1998 \AA$; space group $\mathrm{P} 63 / \mathrm{mmc}$ ). The highest intensity peak is recorded as $d_{110}$ at $2 \theta=26.34^{\circ}$. The clear and sharp powder XRD pattern of the synthesized Bi-MOFs provides enough evidence for the formation of the Bi-MOFs with clear crystalline structure. In the range of $29^{\circ}-31^{\circ}$, there are few peaks assigned to the carbonyl group together with the metal ion. The crystal size is estimated through the Debye-Scherrer formula [13] and is $272.27 \mathrm{~nm}$.

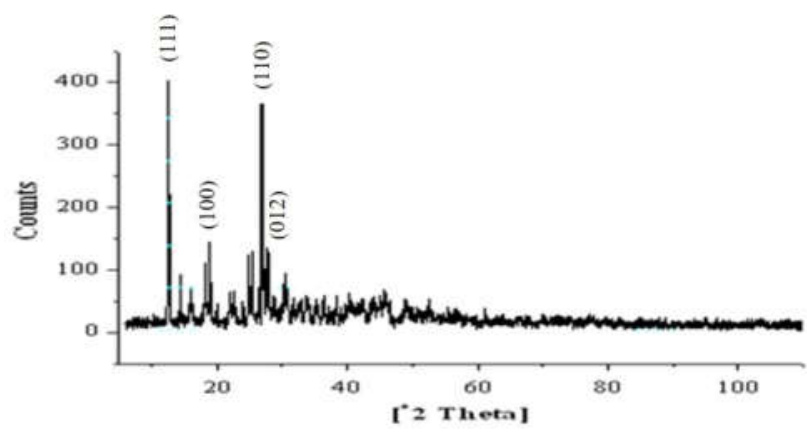

Figure 2. Powder X-ray diffraction (PXRD) pattern of Bi-MOF.
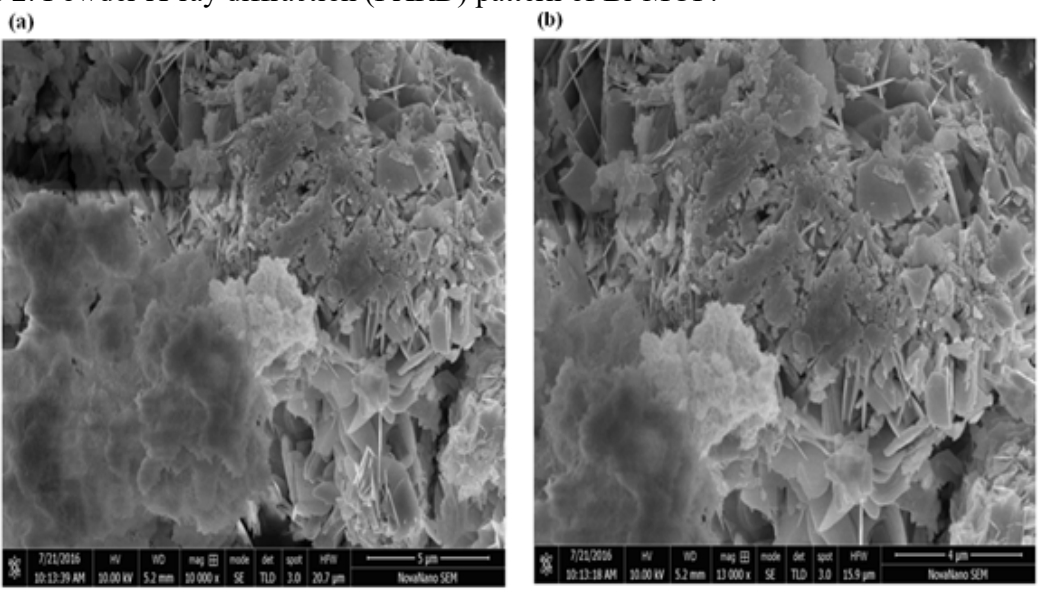

Figure 3. Scanning electron micrograph (SEM) image of bismuth-MOF.

\section{Scanning electron microscopy}

SEM illustrates the shape of Bi-MOF at two different magnification and respective micrographs are shown in Figure 3. These images illustrated that incorporation of metal ions in the organic framework lead to significant changes in morphology. Bismuth-MOF indicated irregular sponge 
shaped particles. One of the most important features of MOFs is their porous structure. For the most part SEM images of this MOF signify porous nature thus making this MOF fit for adsorption phenomenon.

\section{Thermal stability}

TGA was done to check thermal stability of Bi-MOF (Figure 4). The initial weight loss of BiMOF was exhibited between $50-120{ }^{\circ} \mathrm{C}$ and it was seen that continuous breakdown at $380{ }^{\circ} \mathrm{C}$ with weight loss $40 \%$ is due to the decomposition of framework. Finally flat curve is observed due to bismuth oxide as a residual product.

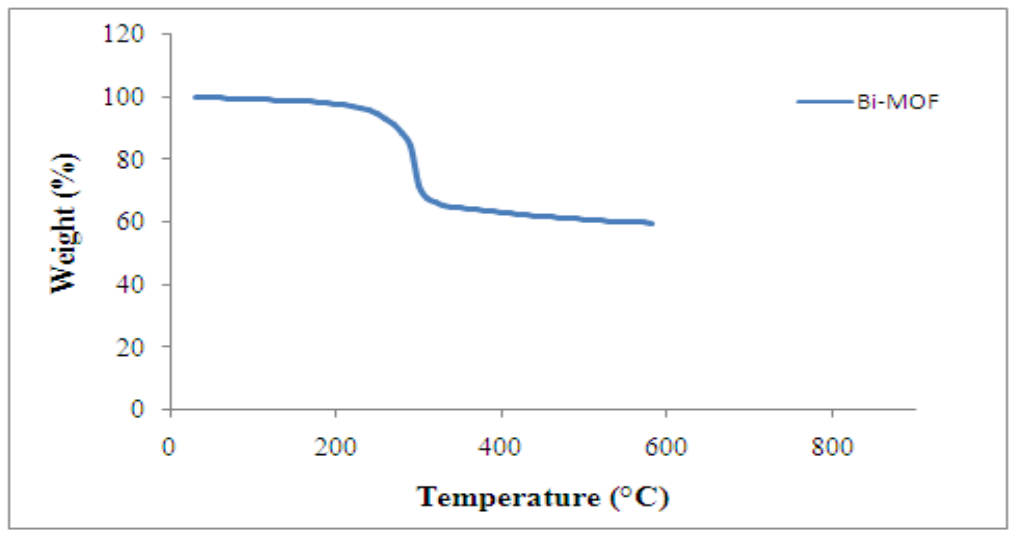

Figure 4. TGA curves of thermal decomposition of bismuth-MOF.

Photoluminescence study

The optical properties of $\mathrm{Bi}^{+3}$ ions are based on different energy levels of Russell-Saunders scheme ${ }^{1} \mathrm{~S}_{0}<{ }^{3} \mathrm{P}_{0}<{ }^{3} \mathrm{P}_{1}<{ }^{3} \mathrm{P}_{2}<{ }^{1} \mathrm{P}_{1}[14]$. Amongst them, the ${ }^{3} \mathrm{P}_{1}{ }^{-} \mathrm{S}_{0}$ state may be caused by the spin-orbit coupling $[14,15]$.

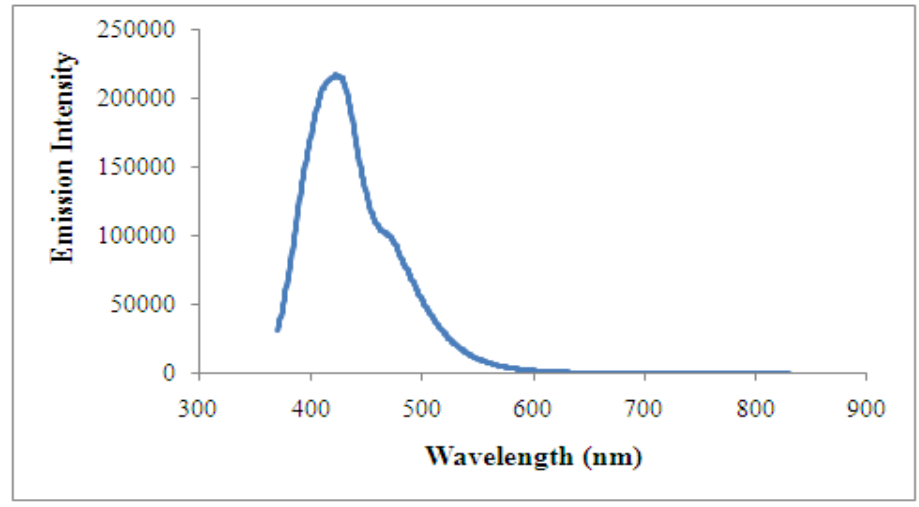

Figure 5. Emission spectrum of bismuth-MOF.

Bull. Chem. Soc. Ethiop. 2021, 35(1) 
The photoluminescence property of Bi-MOF was investigated in the solid state. The emission spectrum is shown in Figure 5. Bi-MOF shows two emission peaks at $438 \mathrm{~nm}$ and 473 $\mathrm{nm}$, which may be designated to ligand-to-metal charge transfer $[16,17]$ or ${ }^{1} \mathrm{P}_{1}-{ }^{1} \mathrm{~S}_{0}$ and ${ }^{3} \mathrm{P}_{1}-{ }^{1} \mathrm{~S}_{0}$ transitions of the " $s$ " electron of $\mathrm{Bi}^{+3}[18,19]$.

\section{Surface area and porosity characterization}

Bi-MOF adsorption isotherms are alike to the type-II isotherm of the BDDT arrangement, compared with single-layer and multi-layer physical adsorption (Figure 6a). Moreover the calculated BET surface area is $1096.11 \mathrm{~m}^{2} / \mathrm{g}$ (Figure 6b), and a significant amount of nitrogen adsorption $(23.74 \mathrm{mmol} / \mathrm{g}$ ) was shown on this MOF, indicating the fact that adsorption selectivity is dependent on polarizability of gas and surface factor [20].
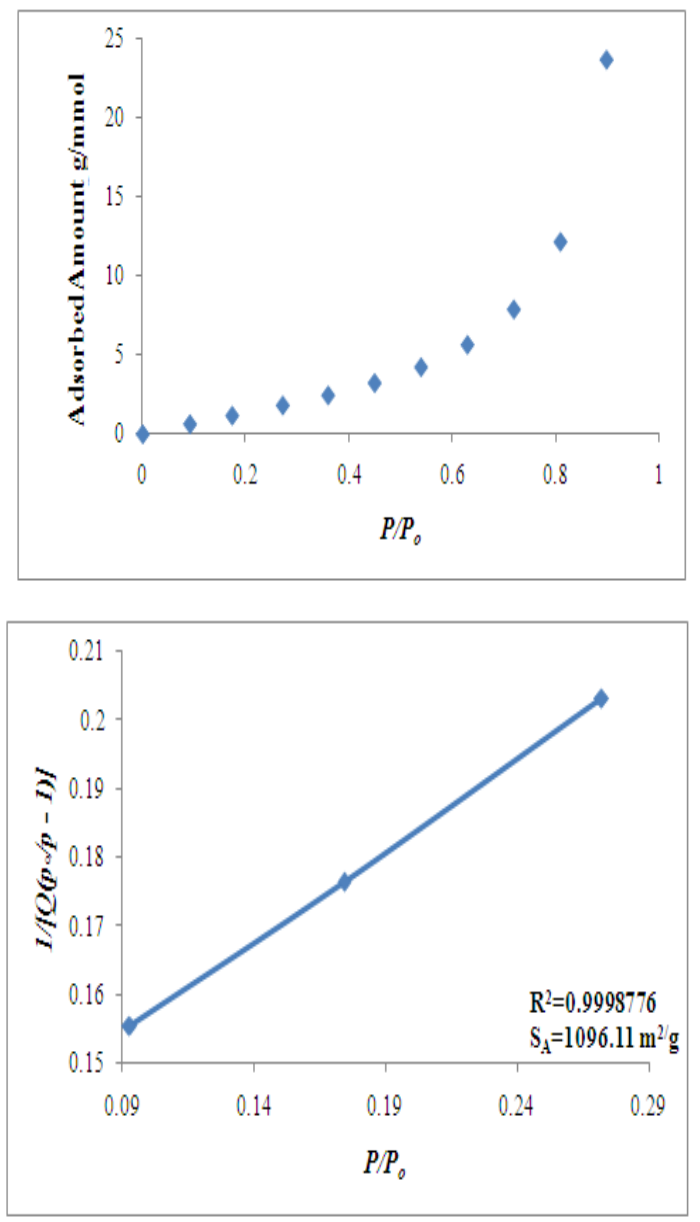

(a)

(b)

Figure 6. (a) $\mathrm{N}_{2}$ isotherm of Bi-MOF and (b) BET analysis of Bi-MOF.

Bull. Chem. Soc. Ethiop. 2021, 35(1) 
Adsorption studies

Keeping in view surface porosity, Bi-MOF was used for the removal of methylene blue dye and various parameters were optimized. Figure $7 \mathrm{a}$ represents the plot of adsorption of methylene blue dye by bismuth-MOF at various $\mathrm{pH}$ that reveal higher adsorption capacity from $\mathrm{pH} 2.0$ to 7.0. While at lower $\mathrm{pH}$ values, since the surface of Bi-MOF is positively charged, the adsorption of the dye is lower, which creates $\mathrm{H}^{+}$particles that has competition with dye $[21,22]$. The optimal $\mathrm{pH}$ value for the MB dye adsorption was 6.0 whereas adsorption of the dye was decreased at higher $\mathrm{pH}(10-12)$ because $\mathrm{OH}^{-}$ions compete effectively with dye ions causing a decrease in sorption of the dye from aqueous solutions.

The sorbent dose value varies between the \% age removal efficiency and adsorption capacity [23]. The adsorption capacity $\mathrm{q}_{\mathrm{e}}(\mathrm{mg} / \mathrm{g})$ changes exponentially with sorbent dose $0.005-0.01$ $\mathrm{mg} / \mathrm{mL}$ with larger sorption capacity, because in that region active sites of Bi-MOF are present. Increasing sorbent dose has less effect on the removal of dye as shown in Figure $7 \mathrm{~b}$.

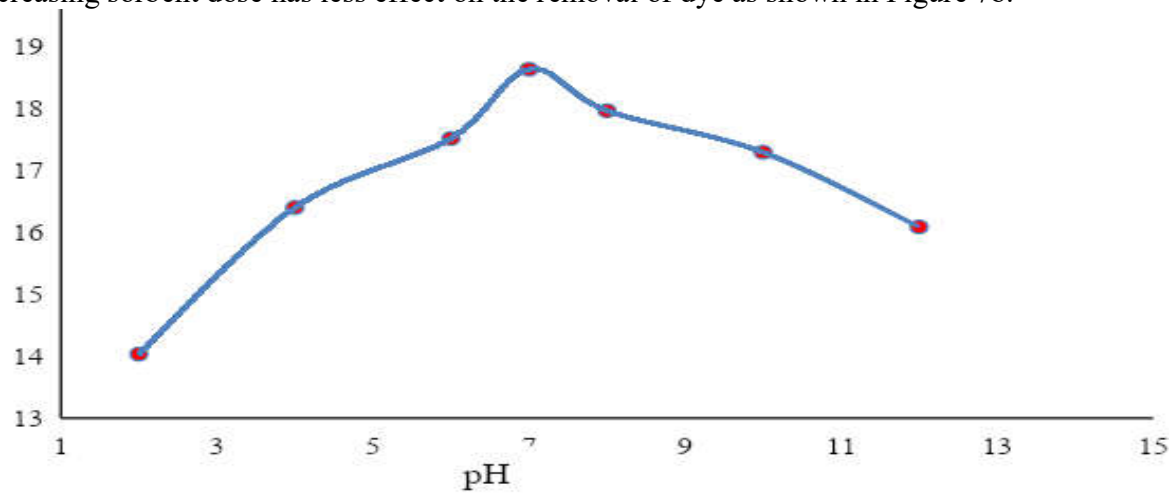

(a)

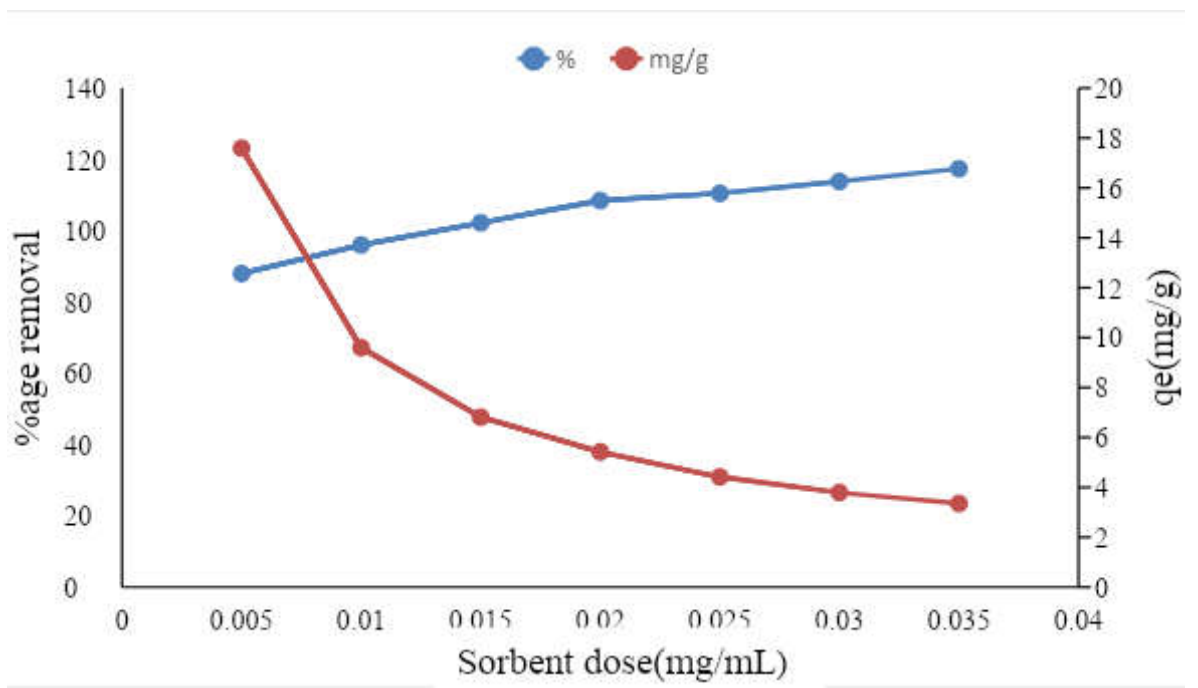

(b)

Figure 7. (a) Effect of $\mathrm{pH}$ and (b) sorbent dose for the removal of methylene blue.

Bull. Chem. Soc. Ethiop. 2021, 35(1) 
The rate of removal of MB from aqueous solution by Bi-MOF and kinetic mechanism are explained by kinetics models ( $1^{\text {st }}$ order and $2^{\text {nd }}$ order kinetics) and the data is shown in Table 1 . In the first $10 \mathrm{~min}$, kinetic uptake is high while after next $10 \mathrm{~min}$ it is slower. It is because in the initial stage there are many void surface sites, and adsorption rate of dye molecules on the outer surface is higher $[24,25]$. Results indicates the pseudo second order $\left(\mathrm{R}^{2}=0.9988\right)$ as the best fit model to explain the adsorption kinetics relative to the pseudo $1^{\text {st }}$ order kinetic model [26]. This demonstrates the chemisorption may be the rate limiting step for MB adsorption.

Table 1. Kinetics models for MB adsorption by Bi-MOF.

\begin{tabular}{|c|c|c|c|c|}
\hline \multirow{2}{*}{ Bi-MOF } & Pseudo $1^{\text {st }}$ order kinetics & $\mathrm{K}_{1}\left(\mathrm{~min}^{-1}\right)$ & $\mathrm{q}_{\mathrm{e}}$ cal. $(\mathrm{mg} / \mathrm{g})$ & $\mathrm{R}^{2}$ \\
\cline { 3 - 5 } & & 0.1842 & 17.862 & 0.9867 \\
\hline Bi-MOF & Pseudo $2^{\text {nd }}$ order kinetics & $\mathrm{K}_{2}\left(\mathrm{~min}^{-1}\right)$ & $\mathrm{q}_{\mathrm{e}}$ cal. $(\mathrm{mg} / \mathrm{g})$ & $\mathrm{R}^{2}$ \\
\cline { 3 - 5 } & & 0.021 & 17.862 & 0.9988 \\
\hline
\end{tabular}

\section{Adsorption isotherms}

The isothermal adsorption models (Langmuir and Freundlich) describe the equilibrium relating to $\mathrm{MB}$ adsorption on Bi-MOF [27]. Table 2 shows the data for Langmuir and Freundlich isotherm plots of adsorption of MB by Bi-MOF. The results showed higher value of correlation coefficient $\left(\mathrm{R}^{2}=0.997\right)$, for Langmuir isotherm, which suggested that this model was the best descriptor of MB adsorption relative to Freundlich isotherm.

Table 2. Isotherm models for MB adsorption by Bi-MOF.

\begin{tabular}{|c|c|c|c|c|c|}
\hline \multirow{2}{*}{ Sorbent } & \multicolumn{5}{|c|}{ Langmuir model } \\
\hline \multirow{3}{*}{ Bi-MOF } & Intercept & Slope & $\mathrm{q}_{\mathrm{m}}(\mathrm{mg} / \mathrm{g})$ & $\mathrm{K}_{\mathrm{L}}(\mathrm{L} / \mathrm{g})$ & $\mathrm{R}^{2}$ \\
\cline { 2 - 7 } & 0.0066 & 0.0609 & 151 & 0.109 & 0.997 \\
\cline { 2 - 7 } & \multicolumn{5}{|c|}{ Freundlich model } \\
\hline \multirow{2}{*}{ Bi-MOF } & Intercept & Slope & $\mathrm{n}$ & $\mathrm{K}_{\mathrm{F}}$ & $\mathrm{R}^{2}$ \\
\cline { 2 - 7 } & 1.2128 & 0.6833 & 1.46 & 16.32 & 0.9942 \\
\hline
\end{tabular}

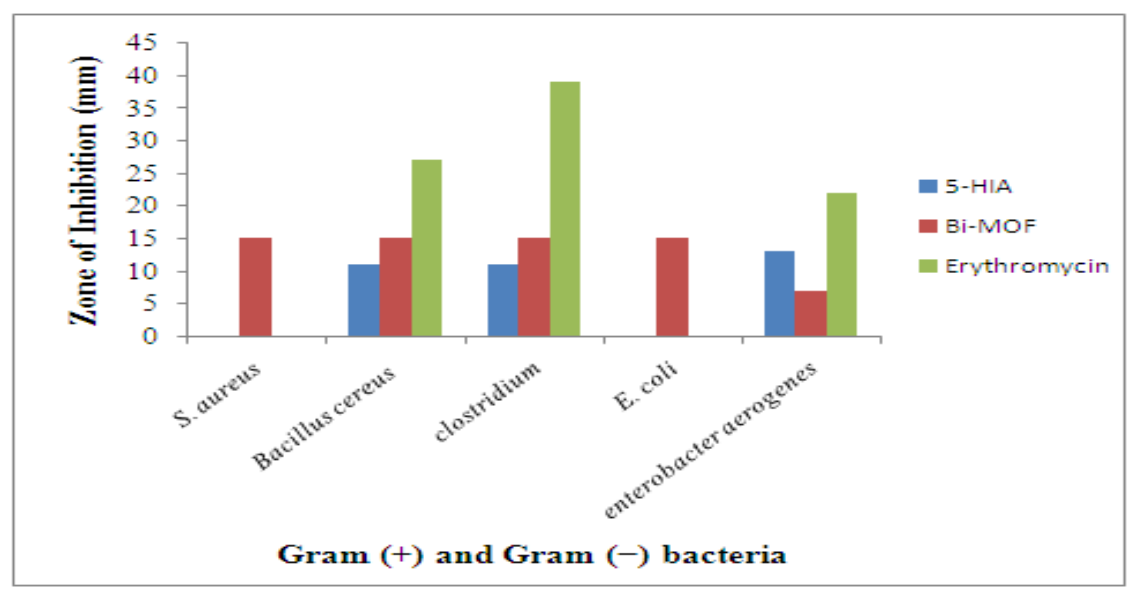

Figure 8. Inhibition zone of bismuth-MOF and reference drugs against Gram-positive and Gram-negative bacteria.

Bull. Chem. Soc. Ethiop. 2021, 35(1) 
Antibacterial activity

The antibacterial activity of 5-hydroxyisophthalic acid (5-HIA) and its corresponding bismuthMOF against five bacterial strains was investigated. Three kinds of Gram-positive bacteria (Staphylococcus aureus, Bacillus cereus and Clostridium) and two kinds of Gram-negative bacteria (E. coli and Enterobacter aerogenes) were used for this purpose while Erythromycin was used as standard drugs. Figure 8 shows the inhibitory effect against these organisms. 5hydroxyisophthalic acid $\left(\mathrm{H}_{2} \mathrm{HIA}\right)$ alone was not much active against all bacterial strains but $\mathrm{Bi}$ MOF showed a moderate activity $(15 \mathrm{~mm})$ against all microorganisms. These results were comparable to that of standard reference drug suggesting the usefulness of Bi-MOF as effective antibacterial agent. Generally, enhance activity of Bi-MOF than uncomplexed linker can be explained on the basis of chelation theory [28].

\section{CONCLUSION}

Bismuth-MOF was successfully synthesized, well characterized and revealed better emission at room temperature. The equilibrium and kinetic batch adsorption studies of Bi-MOF showed a remarkable fast adsorption for MB in aqueous solution. Overall Bi-MOF was explored as a good adsorbent with promising higher textural properties and can be used for the exclusion of many adsorbates such as pollutants and poisonous gases.

\section{REFERENCES}

1. Ma, L.; Abney, C.; Lin, W. Enantioselective catalysis with homochiral metal-organic Frameworks. Chem. Soc. Rev. 2009, 38, 1248-1256.

2. Sonnauer, A.; Hoffmann, F.; Froeba, M.; Kienle, L.; Duppel, V.; Thommes, M.; Serre, C.; Ferey, G.; Stock, N. Giant pores in a chromium 2,6-naphthalenedicarboxylate open-framework structure with MIL-101 topology. Angew. Chem. 2009, 121, 3849-3852.

3. Rowsell, J.L.C.; Yaghi, O.M. Metal-organic frameworks: A new class of porous Materials. Micropor. Mesopor. Mater. 2004, 73, 3-14.

4. Ahnfeldt, T.; Guillou, N.; Gunzelmann, D.; Margiolaki, I.; Loiseau, T.; Senker, J.; Stock, N. $\left[\mathrm{Al}_{4}(\mathrm{OH})_{2}\left(\mathrm{OCH}_{3}\right)_{4}\left(\mathrm{H}_{2} \mathrm{~N}-\mathrm{bdc}\right)_{3}\right] \cdot x \mathrm{H}_{2} \mathrm{O}$ : A 12-connected porous metal-organic framework with an unprecedented aluminum-containing brick. Angew. Chem. 2009, 121, 5265-5268.

5. Dan-Hardi, M.; Serre, C.; Frot, T.O.; Rozes, L.; Maurin, G.; Sanchez, C.M.; Férey, G. A new photoactive crystalline highly porous titanium(IV) dicarboxylate. J. Am. Chem. Soc. 2009, 131, 10857-10859.

6. Thirumurugan, A.; Cheetham, A.K. Anionic metal-organic frameworks of bismuth benzenedicarboxylates: Synthesis, structure and ligand-sensitized photoluminescence. Eur. J. Inorg. Chem. 2010, 3823-3828.

7. Wibowo, A.C.; Smith, M.D.; Zur Loye, H.C. Structural diversity of metal-organic materials containing bismuth(III) and pyridine-2,5-dicarboxylate. Cryst. Growth Des. 2011, 11, 4449-4457.

8. Leonard, N.M.; Wieland, L.C.; Mohan, R.S. Applications of bismuth(III) compounds in organic synthesis. Tetrahedron 2002, 58, 8373-8397.

9. Thirumurugan, A.; Li, W.; Cheetham, A.K. Bismuth 2,6-pyridinedicarboxylates: Assembly of molecular units into coordination polymers, $\mathrm{CO}_{2}$ sorption and Photoluminescence. Dalton Trans. 2012, 41, 4126-4134. 
10. Iornumbe, E.N.; Yiase, S.G.; Sha'Ato, R.; Tor-Anyiin, T.A. Synthesis, characterization and antifungal activity of some organotin(IV) derivatives of octanedioic acid. Int. J. Sci. Res. 2015, 4, 2095-2101.

11. Nakamoto, K. Infrared and Raman Spectra of Inorganic and Coordinated Compounds, 5th ed., John Wiley and Sons: New York; 1997; p 102.

12. Markley, T.J.; Toby, B.H.; Pearlstein, R.M.; Ramprasad, D. New synthesis routes to lithium and cesium cyanide salts. Inorg. Chem. 1997, 36, 3376-3378.

13. Singh, A.K.; Deo, S.R.; Thool, G.S.; Singh, R.S.; Katre, Y.R.; Gupta, A. Synthesis and characterization of chemically deposited nanocrystalline CdSe thin film. Synth. React. Inorg. Met .Org. Nano-Met.Chem. 2011, 41, 1346-1350.

14. Blasse, G.; Meijerink, A.; Nomes, M.; Zuidema, J. Unusual bismuth luminescence in strontium tetraborate $\left(\mathrm{SrB}_{4} \mathrm{O}_{7}: \mathrm{Bi}\right)$. J. Phys. Chem. Solids, 1994, 55, 171-174.

15. Boulon, G.; Moine, B.; Bourcet, J.C.; Reisefeld, R.; Kalisky, Y. Time resolved spectroscopy about ${ }^{3} \mathrm{P}_{1}$ and ${ }^{3} \mathrm{P}_{0}$ levels in $\mathrm{Bi}^{3+}$ doped germanate glasses. J. Lumin. 1979, 1819, 924-928.

16. Wang, X.L.; Chen, Y.Q.; Gao, Q.; Lin, H.Y.; Liu, G.C.; Zhang, J.X.; Tian, A.X. Coordination behavior of 5,6-substituted 1,10-phenanthroline derivatives and structural diversities by coligands in the construction of lead(II) complexes. Crystal Growth Design 2010, 10, 2174-2184.

17. Li, C.P.; Yu, Q.; Chen, J.; Du, M. Supramolecular coordination complexes with 5sulfoisophthalic acid and 2,5-bipyridyl-1,3,4-oxadiazole: Specific sensitivity to acidity for Cd(II) species. Crystal Growth Design 2010, 10, 2650-2660.

18. Folkerts, H.F.; Zuidema, J.; Blasse, G. Different types of " $\mathrm{s}$ ", ion luminescence in compounds with eulytite structure. Chem. Phys. Lett. 1996, 249, 59-63.

19. Srivastava, A.M.; Beers, W.W. On the impurity trapped exciton luminescence in $\mathrm{La}_{2} \mathrm{Zr}_{2} \mathrm{O}_{7}: \mathrm{Bi}^{3+}$. J. Lumin. 1999, 81, 293-300.

20. Suvendu, M.S.; Asamanjoy, B.; Serhiy, D.; Alexandra, K.; Uwe, S.; Christoph, J.; HansJurgen, H. Synthesis of a $\mathrm{Co}(\mathrm{II})$-imidazolate framework from an anionic linker precursor: Gas-sorption and magnetic properties. Crystal Eng. Commun. 2014, 16, 39-42.

21. Hameed, B.H.; Ahmad, A.A. Batch adsorption of methylene blue from aqueous solution by garlic peel, an agricultural waste biomass. J. Hazard. Mater. 2009, 164, 870-875.

22. Ncibi, M.C.; Mahjoub, B.; Seffen, M. Kinetic and equilibrium studies of methylene blue biosorption by Posidonia oceanica (L.) fibres. J. Hazard. Mater. 2007, 139, 280-285.

23. Ahmad, M.; Bachmann, R.T.; Khan, M.A.; Edyvean, R.G.J.; Farooq, U.; Athar, M.M. Dye removal using carbonized biomass, isotherm and kinetic studies. Desalin. Water Treat. 2015, 53, 2289-2298.

24. Dod, G.B.R.; Saini, S. Adsorption of methylene blue using green pea peels (Pisum sativum): A cost-effective option for dye-based waste water treatment. Biotechnol. Bioprocess. Eng. 2012, 17, 862-874.

25. Singh, S.; Sidhu, G.K.; Singh, H. Removal of methylene blue dye using activated carbon prepared from biowaste precursor. Indian Chem. Eng. 2019, 61, 28-39.

26. Ho, Y.S.; McKay, G. Pseudo-second order model for sorption processes. Process. Biochem. 1999, 34, 451-465.

27. Hameed, B.H. Spent tea leaves: A new non-conventional and low-cost adsorbent for removal of basic dye from aqueous solutions. J. Hazard. Mater. 2009, 161, 753-759.

28. Barry, A.L. The Antimicrobial Susceptibility Test, Principles and Practices, 4th ed., ELBS: London; 1976, pp 180-193. 